\title{
Comprehensive determinants of health service utilisation for mental health reasons in a canadian catchment area
}

\author{
Marie-Josée Fleury ${ }^{1 *}$, Guy Grenier ${ }^{2}$, Jean-Marie Bamvita ${ }^{2}$, Michel Perreault ${ }^{1}$, Yan Kestens ${ }^{3}$ and Jean Caron ${ }^{1}$
}

\begin{abstract}
Introduction: This study sought to identify factors associated with health service utilisation by individuals with mental disorders in a Canadian catchment area.

Methods: To be included in the study, participants had to be aged between 15 and 65 and reside in the study location. Data was collected randomly from June to December 2009 by specially trained interviewers. A comprehensive set of variables (including geospatial factors) was studied using the Andersen's behavioural health service model. Univariate, bivariate, and multivariate analyses were carried out.

Results: Among 406 individuals diagnosed with mental disorders, 212 reported using a mental health service at least once in the 12 months preceding the interviews. Emotional problems and a history of violence victimisation were most strongly associated with such utilisation. Participants who were middle-aged or deemed their mental health to be poor were also more likely to seek mental healthcare. Individuals living in neighbourhoods where rental accommodations were the norm used significantly fewer health services than individuals residing in neighbourhoods where homeownership was preponderant; males were also less likely to use services than females.

Conclusions: Our study broke new ground by uncovering the impact of longstanding violence victimisation, and the proportion of homeownership on mental health service utilisation among this population. It also confirmed the prominence of some variables (gender, age, emotional problems and self-perceived mental health) as key enabling variables of health-seeking. There should be better promotion of strategies designed to change the attitudes of males and youths and to deal with violence victimisation. There is also a need for initiatives that are targeted to neighbourhoods where there is more rental housing.
\end{abstract}

Keywords: Mental disorders, Emotional problems, Longstanding violence victimisation, Neighbourhood, Health service utilization

Mental disorders are among the leading causes of morbidity worldwide. In Canada and the United States, depression is the primary source of occupational disability [1-3]. Improving the efficiency of the mental healthcare system, particularly service utilisation, is a priority. According to epidemiological studies, an exceedingly high proportion of individuals with mental disorders do not seek professional help despite the availability of effective treatment [4-9]. A recent meta-analysis of 27 studies found that $26 \%$ of

\footnotetext{
* Correspondence: flemar@douglas.mcgill.ca

'Department of Psychiatry, McGill University, Douglas Hospital Research

Centre, 6875 LaSalle Blvd., Montreal, Quebec H4H 1R3, Canada

Full list of author information is available at the end of the article
}

Europeans sought healthcare for a mental disorder in a 12-month period [10]. Another study, comparing 17 countries, revealed that, in the 10 countries with the highest per-capita income, between $13 \%$ and $61 \%$ of individuals, depending on the severity of their mental disorders, received health services [11,12]. According to the 2002 Canadian Community Health Survey of Mental Health and Well-Being (CCHS 1.2), only 39\% of Canadians used services for mental health reasons [13]. These findings suggest that mental health systems must identify individuals who need care more effectively, and remove clinical and societal barriers to health services.

\section{Biomed Central}

() 2012 Fleury et al; licensee BioMed Central Ltd. This is an Open Access article distributed under the terms of the Creative Commons Attribution License (http://creativecommons.org/licenses/by/2.0), which permits unrestricted use, distribution, and reproduction in any medium, provided the original work is properly cited. 
The most frequently employed tool for identifying factors associated with health service use is the Behavioural Model of Health Service Use [14]. It has been applied to health surveys [15-18] of the general population and mental health studies [9,19-22]. It has also served in studies of older patients with psychiatric problems [23-26], patients with severe mental disorders [27-29], and patients with concurrent problems such as homelessness, substance abuse or violence [30-33].

The Behavioural Model of Health Service Use encompasses individual and contextual dimensions. It classifies predictors of service use into three categories: predisposing, enabling, and needs-related factors. Predisposing factors are individual characteristics that exist prior to the illness (for example, socio-demographic profile, attitudes and values, and knowledge about services). Enabling factors refer to various features that influence care delivery and attitudes toward care; they encompass variables such as income, social support, and availability of care. Finally, needs-related factors include physical and mental health assessment by patients and professionals, for example, illness, symptom severity, perceived needs, and impairment requiring services.

In general, needs-related factors are most closely associated with health service utilisation. Reportedly, several needs-related factors have significant effects on the use of health services: diagnoses of schizophrenia, serious depression [34], and social anxiety behaviour [34].

Among predisposing factors, age, gender, marital status, education, country of birth, and race/ethnicity are significant determinants of service utilisation among individuals with mental disorders. Several studies have found that younger (18-24) and older (65 and up) individuals were less likely to use services than participants aged 25 to 64 $[8,34,35]$. Females were the most frequent users of health services, principally of general practitioners; men were more likely to seek specialised services [2,29,34,36-39]. Studies have found that persons who were previously or currently married used services more often than bachelors $[2,8,40,41]$. Individuals with more education [2,34] also used health services significantly more often than less-educated persons, despite the higher incidence of mental disorder among the latter [42]. With regard to country of birth, race and ethnicity, studies found that Whites are more likely to use health services than Blacks or immigrants $[2,30,33,43]$. Attitudes and beliefs regarding mental health and treatment and knowledge also played a role in service use. High rates of health service use have been found among individuals who consider their mental health to be poor [34] and maternal history of mental illness [5].

Among enabling factors, perceived barriers to accessibility to care were negatively associated with service utilisation [34]. Individuals with more elevated socio-economic status tended to use specialised services more assiduously, particularly psychiatric and psychological care, even among individuals with the same insurance coverage [2,44-46]. Family and social support can be positively or negatively associated with service utilisation $[29,47,48]$. Some social networks helped individuals to recognise their problems and seek aid from health providers; other networks tended not to encourage members to seek help, thereby constituting a barrier to accessibility [49]. Professional support also played a role $[31,50]$. Access to a regular source of medical care was positively associated with service utilisation [34].

If previous studies have found several variables associated with health service utilisation for mental health reasons, some variables such as religious beliefs, neighbourhood/geospatial information, involvement in the justice system, impulsivity, and lifetime of aggressive behavior and violence, have received little or no attention in the literature to our knowledge. Some studies have found that churches were a significant factor of social integration in certain communities, and that church involvement was negatively associated with depressive symptoms. Concerning neighbourhood/geographical variables, living in socio-economically deprived areas or socially disorganised neighbourhoods was associated with psychosocial stress and higher incidence of depressive symptoms [51]. Finally, past or present experiences of violence, crime or imprisonment were all associated with higher prevalence of mental disorders [52] or emotional problems [53,54]. Those variables that were positively or negatively associated with the prevalence of mental disorders could also play a role in health service utilisation for mental health reasons.

This study sought to identify factors of health service utilisation among individuals diagnosed with a mental disorder in a 12-month period within a Canadian urban catchment area of 258,000 inhabitants. A comprehensive set of variables comprising geospatial factors was analysed using the Andersen's behavioural model [14], which posits that health service use is determined by predisposing, enabling, and needs-related factors. We hypothesised that some novel variables associated with the prevalence of mental disorders in the general population (e.g. neighbourhood or geospatial data, involvement in the justice system), based on a holistic set of variables, could also play a role in health service utilisation.

\section{Methods}

\section{Study design and setting}

This study focused on a catchment area in the southwestern sector of Montreal, Canada with a population of 258,000. The area encompasses a diverse mix of residents as well as a broad range of social structures, socio-economic status, education, availability of health services, neighbourhood dynamics, and levels of security. 
The study area included six neighbourhoods ranging in population from 29,205 to 72,4200 [55]. Immigrants represented $17 \%$ of the population (as compared with $26 \%$ in Montreal). The proportion of low-income households was $36 \%$ (as compared with 23\% in the province of Quebec and $35 \%$ in Montreal). Low-income households were located mainly in two of the four neighbourhoods where nearly half of residents are low-income earners. Previous studies revealed a high incidence of psychological distress in low-income populations at this location [55]. Mental health services are chiefly delivered by three organisations: two health and social service centres (created through the merger of a general hospital, community local service centres, and nursing homes) that provide first-line (basic bio-psycho-social services offered to the population with common mental disorders) and second-line (specialized services) health services. A psychiatric hospital delivers second- and third-line services (ultra-specialized for individuals who present highly complex health problems). Sixteen community-based agencies offering mental health services were also present; they provided numerous services (for example, a crisis centre, day centres, self-help groups, back-to-work programs) to individuals with mental disorders or their relatives. General practitioners and psychologists in private clinics completed the mental health offer in this area.

\section{Selection criteria and sample}

To be included in the survey, participants had to be aged from 15 to 65 and be residents of the target area. The objective was to obtain a representative sample of the targeted population, both geographically, i.e. recruiting participants across the area, as well as in proportion to the population density and in terms of socio-economic status (SES), that is, representative of the educational attainment profile of the area. A target sample of 3,708 addresses was selected for recruitment. Participants were first contacted by phone, and 300 individuals were recruited. It was soon decided, however, to proceed otherwise due to the low response rate compared to the number of potential participants who were randomly selected. In order to improve recruitment, 13 nearby addresses were added to each address that was originally selected. This range of 14 potential addresses thus included the original address, the three addresses that were the closest on each side, and the seven addresses on the opposite side of the street. We used 3,408 addresses for door-to-door recruitment; the 3,408 original addresses hence resulted in 3,408*14 nearby addresses, theoretically representing 47,712 potential addresses where individuals would be available for recruitment. The recruiters met 7,265 individuals in person and, from those, 3,726 (51\%) refused to participate. Amongst the 3,539 individuals who accepted to participate, 1,405 (19\%) were not eligible; 2,134 participants completed the interview for a response rate of $49 \%$. The response rate is superior to the median rates reported in epidemiological studies of populations conducted in the years since 2000, when there had been a steady decline in participation rates over the past 30 years $[56,57]$.

The sample was equally distributed in the study area among the various neighbourhoods. Data was collected randomly from June to December 2009 by specially trained interviewers. Only one person per target household was selected using procedures and criteria contained in the National Population Health Survey [58]. For purposes of recruitment, the interviewers had phone contacts with individuals who agreed to participate in the study within the week during which they were recruited, in order to schedule a face-to-face meeting either at the participant's home or in an office designated for that purpose at the psychiatric hospital. Most interviews, however, were conducted at the participant's home. The face-to-face interview was conducted once a consent form was signed, and lasted from a minute and a half to three hours depending on whether a mental disorder was detected or not. Interviewers used portable computers. The research was approved by relevant ethics boards.

A randomly selected sample of 2,434 individuals took part of the survey. Women were overrepresented (62\%) in the final study sample, compared to the reference population (52\%); men under the age of 45 were underrepresented. To ensure a precise prediction of the prevalence of mental illness in the population, we weighted the data for sex and age. The mean age was 40,72 (ET $=14,08)$. The make-up of respondents was as follows: $49 \%$ were men, $38 \%$ were single, $45 \%$ were married or in a relationship, $12 \%$ were divorced or separated, and $71 \%$ had a post-secondary diploma; 79\% were employed in the last 12 months and $25 \%$ were immigrants; French was the primary language spoken by $54 \%$ of the respondents, followed by English as the primary language for $22 \%$; Whites accounted for $81 \%$ of the sample. The average personal income was $\$ 31,192 \mathrm{CAD}(\mathrm{sd}-33)$ and the average family income $\$ 59,056 \mathrm{CAD}$ ( $\mathrm{sd}=\$ 49,851$ ); $33 \%$ of the respondents were considered as having a low income and $67 \%$ had extremely low or no income. Among the 2,434 individuals who took part in the survey, 406 had experienced at least one episode of mental health disorder in the 12 months preceding the interview, and were selected for the analyses described below.

\section{Variables and measurement instruments}

Variables assessed in this study are displayed in Table 1 and categorised according to the behavioural model [14]. Instruments used to measure specific health and psychosocial parameters are described in Table 2.

The dependent variable refers to individuals diagnosed with mental disorders in the previous 12 months 
Table 1 Variables assessed in the study

\begin{tabular}{|c|c|c|}
\hline & & Variables \\
\hline \multirow[t]{13}{*}{ Predisposing factors } & \multirow[t]{7}{*}{ Socio-demographic Variables' } & Age \\
\hline & & Gender \\
\hline & & Marital status \\
\hline & & Household composition and size \\
\hline & & Education \\
\hline & & First language \\
\hline & & Country of birth \\
\hline & \multirow[t]{2}{*}{ Religious beliefs } & Importance attributed to spirituality \\
\hline & & Frequency of participation in religious activities \\
\hline & \multirow[t]{2}{*}{ Health beliefs } & Quality of life \\
\hline & & Self-perception of mental and physical health ${ }^{i}$ \\
\hline & Knowledge & Parental Psychiatric History \\
\hline & Justice system $^{i}$ & History of imprisonment \\
\hline \multirow[t]{14}{*}{ Enabling factors } & Economic factors & Income (personal, household; main source) \\
\hline & \multirow[t]{2}{*}{ Territory } & Neighbourhood ${ }^{i v-x}$ \\
\hline & & Neighbourhood characteristics ${ }^{i v-i x}$ \\
\hline & \multicolumn{2}{|l|}{ Social support ${ }^{\mathrm{xi}}$} \\
\hline & \multicolumn{2}{|l|}{ Social stigma ${ }^{x i}$} \\
\hline & Geospatial variables' & Walking distance to health services \\
\hline & & Driving distance to health services \\
\hline & & Proportion of rental accommodations \\
\hline & & Proportion of individuals who moved a year ago \\
\hline & & Unemployment rate among the population aged 25 and up \\
\hline & & Active population aged 15 and up \\
\hline & & Average household income after taxes \\
\hline & & Average household income after taxes \\
\hline & & Proportion of recent immigrants \\
\hline \multirow[t]{6}{*}{ Needs } & \multicolumn{2}{|l|}{ Number of mental disorders ${ }^{\text {xiii-xvi }}$} \\
\hline & \multicolumn{2}{|l|}{ Lifetime victim of violence } \\
\hline & \multicolumn{2}{|l|}{ Lifetime aggressive behaviour ${ }^{x v i}$} \\
\hline & \multicolumn{2}{|l|}{ Psychological distress ${ }^{x v i i}$} \\
\hline & \multicolumn{2}{|l|}{ Impulsiveness $^{x \text { viii }}$} \\
\hline & \multicolumn{2}{|l|}{ Emotional problems ${ }^{i}$} \\
\hline Health service utilisation & \multicolumn{2}{|c|}{$\begin{array}{l}\text { Services are provided in hospitals (including hospitalisation), mental health community centres, rehabilitation centres, } \\
\text { private clinics, pharmacies, and in the voluntary sector (e.g. support groups, crisis-line services). Professionals consulte } \\
\text { included psychologists, general practitioners, psychiatrists, case managers, toxicologists, nurses, social workers, } \\
\text { psychotherapists, pharmacists, other health professionals. }\end{array}$} \\
\hline
\end{tabular}

who have used health services due to mental health problems.' Participants who were diagnosed as having at least one mental disorder were invited to identify services that they used to deal with their condition. Individuals had one of the following diagnoses: major depressive disorder, mania, social phobia, agoraphobia, panic disorder, post-traumatic stress disorder, or alcohol and drug dependence. Mental disorders were identified with the CCHS 1.2 version of the Composite International Diagnostic Interview (CIDI) [74], used in the
Global Survey on Mental Health (WMH, 2000). This is a diagnostic tool that generates psychiatric diagnoses according to the definitions and criteria of ICD 10 and DSM IV. Alcohol and drug dependency were assessed using a short form of the CIDI (based upon the DSMIII-R criteria). Previous versions of the CIDI have demonstrated reliability and validity [75]. The questionnaire on the use of mental health services was also adapted from the CCHS 1.2. Health services refer to one of the following services or professionals: hospital 
Table 2 Measurement instruments

\begin{tabular}{|c|c|c|c|}
\hline & & Name & Description \\
\hline \multirow[t]{3}{*}{$\begin{array}{l}\text { Predisposing } \\
\text { factors }\end{array}$} & $\mathrm{i}$ & $\begin{array}{l}\text { Canadian Community Health Survey } \\
\text { (CCHS) } 1.2 \text { (Statistics Canada, 2001)* }\end{array}$ & $\begin{array}{l}\text { Survey questionnaire for socio-demographic characteristics; yes/no and multiple } \\
\text { choice questions; Likert and non-Likert scale questions }\end{array}$ \\
\hline & ii & $\begin{array}{l}\text { Satisfaction with Life Domains Scale (SLDS) } \\
\qquad[59]^{\mathrm{a}}\end{array}$ & 20 items; seven-point Likert scale questions; Cronbach alpha: 0.92 \\
\hline & iii & Parental Psychiatric History (PPH) [60] & Measures mental disorders in parents and relatives; yes/no questions \\
\hline \multirow{9}{*}{$\begin{array}{l}\text { Enabling } \\
\text { factors }\end{array}$} & iv & Sense of Community Scale (SCS) [61] & 8 items; Cronbach alpha: 0.74 \\
\hline & $\mathrm{v}$ & Community Participation Scale (CPS) [62] & 6 items; yes/no and four-point Likert scale questions; Cronbach alpha: 0.73-0.89 \\
\hline & $\mathrm{vi}$ & Resident Disempowerment Scale (RDS) [63] & 3 items \\
\hline & vii & Sense of Collective Efficacy (SCE) [64] & $\begin{array}{l}\text { Evaluate the effect of social and institutional mechanisms on individuals living in } \\
\text { the neighbourhood; Cronbach alpha: } 0.80-0.91\end{array}$ \\
\hline & viii & Neighbourhood Disorder Scale (NDS) [63] & 9 items; Cronbach alpha: 0.84 \\
\hline & ix & $\begin{array}{l}\text { Physical Conditions of the Neighbourhood } \\
\text { (PCN) [61] }\end{array}$ & 7 items; Cronbach alpha: 0.87 \\
\hline & $x$ & Facility in Neighbourhood (FN) [65] & 13 items; ten-point Likert scale questions; Cronbach alpha: 0.40 to 0.90 \\
\hline & xi & Social Provisions Scale (SPS) [66] ${ }^{a}$ & 24 items; four-point Likert scale questions; Cronbach alpha: 0.92 \\
\hline & xii & Devaluation-Discrimination Scale (DDS) [67] & 12 items; six-point Likert scale questions; Cronbach alpha: 0.68-0.99 \\
\hline \multirow[t]{6}{*}{ Needs } & xiii & $\begin{array}{l}\text { Composite International Diagnostic } \\
\text { Interview (CIDI), (Statistics Canada, 2000)* }\end{array}$ & $\begin{array}{c}\text { Screening of mental disorders; was used in the World Mental Health, } 2000 \text { [68]; } \\
\text { included the most frequent mental disorders (depression, bipolar disorder, mania, } \\
\text { post-traumatic stress disorder, anxiety disorders: social phobia, agoraphobia, and } \\
\text { panic disorder) }\end{array}$ \\
\hline & xiv & Drug Abuse Screening Test (DAST) [69]* & 20 items; yes/no questions; Cronbach alpha: 0.74 \\
\hline & $x v$ & 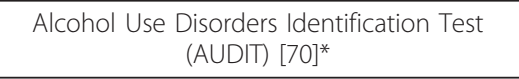 & 10 items; 2 or multiple choice questions; Cronbach alpha: 0.88 \\
\hline & $\mathrm{xvi}$ & $\begin{array}{l}\text { Modified Observed Aggression Scale } \\
\text { (MOAS) for Aggressive Behaviors [71]* }\end{array}$ & $\begin{array}{c}\text { Assess } 4 \text { categories of aggressive behaviour: verbal aggression, aggression to } \\
\text { propriety, self-inflicted aggression, physical aggression }\end{array}$ \\
\hline & xvii & $\begin{array}{l}\text { K-10 Psychological Distress Scale (K-10 } \\
\text { PDS) [72]* }\end{array}$ & $\begin{array}{l}10 \text { items; five-point Likert scale questions; area under the receiver operating } \\
\text { characteristic curve of SMI: } 0.854\end{array}$ \\
\hline & xviii & Barratt Impulsivity Scale (BIS) [73]* & 30 items; four-point Likert scale questions \\
\hline
\end{tabular}

*: Measurement instruments validated in the French-speaking population

bed, rehabilitation centre, psychologist, general practitioner, psychiatrist, case manager, toxicologist, nurse, social worker, psychotherapist, pharmacist, support group, telephone support, or other health professionals. At least one of the above consultations in the previous 12 months was considered as use of mental health services.

Predisposing factors included socio-demographic variables (age, gender, marital status, household composition and size, education, first language, country of birth), religious beliefs (importance attributed to spirituality and frequency of participation in religious activities), health beliefs (quality of life, self-perception of mental and physical health), knowledge (parental psychiatric history) and justice system (history of imprisonment). Enabling factors included variables associated with income (personal, household and main source), territory, social support, social stigmatisation and spatial variables of the social and built characteristics of the local residential area. A geographic information system was used to compute proximity to the closest health service, and measures of local area socio-economic statues (SES). Proximity measures were obtained by calculating the traveling distance between a participant's home and the closest health service, either using pedestrian roads or the motor vehicle network. Measures of area social composition, obtained from the 2006 Census at the dissemination area level, were re-compiled for each participant's local residential area using ego-centered circular buffers of 500 metres [76]. Such ego-centered methods, providing individualised measures of local areas, make it possible to use environmental predictors in classical regression models at the individual level. Measures of local area SES included the following: proportion of renters and recent movers, unemployment rate, active population level, household income and number of recent immigrants. Finally, needs-related factors included the number of mental disorders diagnosed in the 12 months preceding the interview: psychological distress, impulsiveness, and emotional problems as well as longstanding violence victimisation and longstanding aggressive behaviour. 


\section{Analyses}

Univariate, bivariate, and multivariate analyses were carried out. Univariate analyses entailed the calculation of the frequency distribution for categorical variables and mean values for continuous variables. In bivariate analyses, a single logistic regression was used to assess variables associated with health service utilisation in the 12 months prior to the interview, with the Alpha value set at $\mathrm{P}<0.10$. Variables that yielded a significant association in bivariate analyses were introduced into the multiple model through the application of the backward likelihood ratio elimination technique [77], with the Alpha value set at $\mathrm{P}<0.05$. The Hosmer-Lemeshow test was applied to assess the model goodness-of-fit and a Nagelkerke R square was generated to express the proportion of variance explained by the model.

\section{Results}

Among the 406 individuals who have experienced at least one episode of mental health disorder in the 12 months preceding the interview and were selected for the analyses described below, 212 (52\%) reported at least one occurrence of health service use.

The distribution characteristics of the 406 participants are displayed in Tables 3 and 4. The sample was 56\% female. The mean age was 39 (SD: 13.1). Eighty-one percent were Canadian-born. Mental and physical health was deemed to be very good or excellent, respectively, by $24 \%$ and $27 \%$ of participants. Approximately half (51\%) reported that they were satisfied or very satisfied with their lives. Almost half was employed (45\%). Only 13\% reported receiving social assistance. The mean household income was $\$ 43,650$ CAD (SD: $\$ 38,179$; Minimum: 0; Maximum: $\$ 228,000.00)$. The mean score for quality of life was 94.7 (SD: 18.2; Minimum: 26; Maximum: 131). The three mental health disorders most frequently reported were major depressive episode (52\%), alcohol dependence (24\%), and social phobia (20\%). More than half $(57 \%)$ of the participants reported having experienced emotional problems in the 12 months before the interview. Forty-nine percent declared being lifetime victims of violence, and $47 \%$ had a history of aggressive behaviour.

The distribution characteristics of the 212 participants who used health services are also displayed in Tables 3 and 4 . Individuals who used health services were more often female and dissatisfied or highly dissatisfied with their quality of life; in addition, they deemed their mental and physical health to be fair or poor. These individuals also tended to be longstanding victims of violence or had a long history of aggressive behaviour. Compared with the sample of 406 as a whole, individuals who used health services also had more frequent emotional problems, ser- ious depressive episodes or agoraphobia in the last 12 months.

\section{Multiple model}

Variables significantly associated with service utilisation in bivariate analyses are displayed in Table 5 . Bivariate linear analyses yielded five predisposing, four enabling, and three needs-related variables significantly associated with health service use.

The multiple logistic regression model built using these variables and the backward elimination technique retained six variables. Variables associated with needsrelated factors were the most strongly correlated variables in the model. Participants who reported emotional problems in the 12 months before the interview had a four-fold probability increase in health service use. Those who reported being longstanding victims of violence were twice as likely to use services. Among predisposing factors, perception of mental health, gender, and age emerged, with age as the most strongly associated variable in this category: older participants were more likely than younger participants to use services. Individuals who view their mental health as poor were $73 \%$ more likely to use services. Female participants were $49 \%$ more likely to use services. Finally, among enabling factors, only one variable was associated, negatively, with health service utilisation: proportion of rental housing. Individuals living in neighbourhoods where renters outnumber homeowners used fewer health services. The model's goodness-of-fit was very adequate, as shown by the Hosmer-Lemeshow test, with 34\% variance expressed.

\section{Discussion}

This study aimed to assess variables associated with health service utilisation by individuals diagnosed with mental disorders within a 12-month period in an urban setting in Montreal, Canada. Using the Andersen's behavioural model as a guide, a holistic set of variables categorised into the following domains was taken into consideration: predisposing, enabling, needs-related (independent variables), and service utilisation (dependent variable). To the most salient variables associated with health services utilisation according to the literature, we have added some novel variables (e.g., involvement in the justice system, neighbourhood and geospatial data), and hypothesised that some of these could also play a role in health services utilisation for mental health reasons.

Interestingly, roughly half of the 406 individuals who experienced a mental disorder in the past year self-rated their mental health as good and said they were highly satisfied with their life. Individuals who used health services had a worse perception of their mental health and lower life satisfaction, compared to individuals who 
Table 3 Frequency distribution of participants with mental disorders in the 12 months before the interview $(\mathrm{N}=\mathbf{4 0 6}$ )

\begin{tabular}{|c|c|c|c|c|c|c|c|}
\hline & & \multicolumn{3}{|c|}{$\begin{array}{l}\text { Distribution of the entire } \\
\text { sample of participants } \\
\text { ( } N=406)\end{array}$} & \multicolumn{2}{|c|}{$\begin{array}{l}\text { Participants } \\
\text { who have } \\
\text { used health } \\
\text { services } \\
(\mathrm{N}=212)\end{array}$} & \multirow[t]{2}{*}{$\begin{array}{l}P \text { value (used versus did not } \\
\text { use health services) }\end{array}$} \\
\hline & & & $\mathrm{n}$ & $\%$ & $\mathrm{n}$ & \%* & \\
\hline \multirow{13}{*}{$\begin{array}{l}\text { Predisposing } \\
\text { factors }\end{array}$} & Gender & Female & 229 & 56.4 & 134 & 58.5 & .157 \\
\hline & & Male & 177 & 43.6 & 78 & 44.1 & \\
\hline & Country of birth & Canada & 329 & 81.0 & 142 & 43.2 & .001 \\
\hline & & Other & 68 & 15.1 & 32 & 47.1 & \\
\hline & Self-perception of mental health & Excellent/Nery good & 99 & 24.4 & 33 & 33.3 & $<.001$ \\
\hline & & Good & 170 & 41.9 & 91 & 53.5 & \\
\hline & & Fair/Poor & 137 & 33.7 & 87 & 63.5 & \\
\hline & Self-perception of physical health & Excellent/Very good & 111 & 27.4 & 50 & 45.0 & $<.001$ \\
\hline & & Good & 145 & 35.7 & 74 & 51 & \\
\hline & & Fair/Poor & 150 & 36.9 & 88 & 58.7 & \\
\hline & General satisfaction with life & $\begin{array}{l}\text { Very satisfied/ } \\
\text { Satisfied }\end{array}$ & 208 & 51.3 & 97 & 46.6 & $<.001$ \\
\hline & & $\begin{array}{l}\text { Neither satisfied nor } \\
\text { dissatisfied }\end{array}$ & 111 & 27.3 & 60 & 54.1 & \\
\hline & & $\begin{array}{l}\text { Dissatisfied/Nery } \\
\text { dissatisfied }\end{array}$ & 83 & 20.4 & 53 & 63.9 & \\
\hline \multirow{5}{*}{$\begin{array}{l}\text { Enabling } \\
\text { factors }\end{array}$} & Main source of income & Salary & 183 & 45.1 & 99 & 54.1 & .258 \\
\hline & & Social welfare & 52 & 12.8 & 25 & 48.1 & .572 \\
\hline & & $\begin{array}{l}\text { Rent or retirement } \\
\text { pension }\end{array}$ & 19 & 4.7 & 8 & 42.1 & .024 \\
\hline & & $\begin{array}{l}\text { Unemployment } \\
\text { insurance }\end{array}$ & 11 & 2.7 & 5 & 45.5 & .258 \\
\hline & & Other & 17 & 4.1 & 9 & 56.3 & .090 \\
\hline \multirow[t]{11}{*}{ Needs } & Emotional problems in the 12 months pre-in & erview & 230 & 56.7 & 161 & 70.0 & $<.001$ \\
\hline & Lifetime victim of violence & & 198 & 48.8 & 133 & 67.2 & $<.001$ \\
\hline & Lifetime aggressive behaviour & & 191 & 47.0 & 117 & 61.3 & $<.001$ \\
\hline & $\begin{array}{l}\text { Types of mental health disorders in the } 12 \\
\text { months pre-interview }\end{array}$ & $\begin{array}{l}\text { Major depressive } \\
\text { episode }\end{array}$ & 209 & 51.5 & 129 & 61.7 & $<.001$ \\
\hline & & Alcohol dependence & 97 & 23.9 & 43 & 44.3 & $<.001$ \\
\hline & & Social phobia & 80 & 19.7 & 41 & 51.3 & .001 \\
\hline & & Drug dependence & 77 & 19.0 & 34 & 44.2 & $<.001$ \\
\hline & & Mania & 45 & 11.1 & 23 & 51.1 & $<.001$ \\
\hline & & Panic disorder & 44 & 10.8 & 22 & 50.0 & .002 \\
\hline & & Agoraphobia & 29 & 7.1 & 19 & 65.5 & .017 \\
\hline & & $\begin{array}{l}\text { Post-traumatic stress } \\
\text { disorder }\end{array}$ & 18 & 4.4 & 8 & 44.4 & .094 \\
\hline
\end{tabular}

didn't use health services. It is impossible to say, however, if the former truly have better mental health or if they underestimate their mental health problems.

Most studies have shown that about $33 \%$ of individuals with mental disorders used health services to treat their condition $[78,79]$. In our study, almost $50 \%$ of individuals diagnosed with mental disorders in the 12 past months did not seek professional help for their problems, despite universal healthcare access. It may be that most individuals used mental health services only when they believe that their disorders were severe, chronic or disabling or when they thought that professionals could significantly help them [80]. The proximity of a psychiatric hospital may explain the observed increased use of health services in the catchment area. Usually, individuals with mental disorders tend to live near their treatment centre. Furthermore, needs are more numerous in deprived urban areas $[81,82]$. Another reason why our study showed a 
Table 4 Descriptive statistics of participants with mental disorders in the 12 months before the interview

\begin{tabular}{|c|c|c|c|c|c|c|c|c|}
\hline & \multicolumn{8}{|c|}{$(\mathrm{N}=406)$} \\
\hline & & \multicolumn{3}{|c|}{$\begin{array}{l}\text { Distribution of the entire } \\
\text { sample of participants }(\mathrm{N}= \\
406)\end{array}$} & \multirow[b]{2}{*}{ SD } & \multicolumn{2}{|c|}{$\begin{array}{l}\text { Participants who } \\
\text { have used health } \\
\text { services ( } \mathrm{N}= \\
212 \text { ) }\end{array}$} & \multirow{2}{*}{$\begin{array}{l}P \\
\text { value } \\
P \\
\text { value }\end{array}$} \\
\hline & & Minimum & Maximum & Mean & & Mean & SD & \\
\hline Predisposing factors & Age & 16 & 69 & 39.40 & 13.11 & 40.89 & 12.65 & .088 \\
\hline \multirow[t]{2}{*}{ Enabling factors } & Quality of life SLDS score* & 26 & 131 & 94.73 & 18.19 & 93.21 & 19.64 & $<.001$ \\
\hline & Total household income & 0 & 228000.00 & 43650.03 & 38179.43 & 43313.75 & 36478.15 & .026 \\
\hline \multirow{2}{*}{$\begin{array}{l}\text { Needs-related } \\
\text { factors }\end{array}$} & Psychological distress score & 1.00 & 37.00 & 15.6755 & 7.75732 & 16.2786 & 7.65919 & $<.001$ \\
\hline & Number of mental health disorders per subject & 1 & 3 & 0.34 & 0.640 & 0.32 & 0.636 & .760 \\
\hline $\begin{array}{l}\text { Health service } \\
\text { utilisation }\end{array}$ & $\begin{array}{l}\text { Number of health services used in the previous } \\
12 \text { months }\end{array}$ & 0.00 & 8.00 & 1.8715 & 1.38426 & 2.1 & 1.964 & $<.001$ \\
\hline
\end{tabular}

*Satisfaction with Life Domains Scale (SLDS) score varies from 20 to 140 - the least or worst possible score to the best score

** K-10 psychological distress scale (K-10 PDS) varies from 10 to 50 - the best possible score to the worst score

higher number of users could be that, inversely to other studies $[78,79]$, ours included only individuals aged between 15 and 65 years old. Individuals over 65 years are less likely to use services than middle-aged individuals $[8,34,35]$.

In accordance with the Andersen's theory, needsrelated factors were the prime predictors of health service utilisation in our study [14]. The close association between emotional problems and service use could be linked to the pain experienced by individuals who recognise their emotional problems, leading them to seek professional help. Emotional problems are often linked in studies with interpersonal relationships [83]. According to Caron and colleagues, lack of emotional support and presence of persons perceived as stressful are the most significant predictors of psychological distress [84]. Some studies found an association between marital distress and mental health service use $[83,85,86]$. While marital concord is consistent with healthy sleep habits, fewer signs of depression, and fewer visits to the doctor's office, conjugal discord raises the risk of mental and physical dysfunction [86]. The loss of a relationship and the resulting social isolation has been shown to increase the use of health services by those who are separated, divorced or widowed $[8,40,41]$.

With regard to longstanding victims of violence, several studies have revealed that exposure to violence intensifies stress and gives rise to feelings of vulnerability, thereby

Table 5 Variables associated with health service utilisation by individuals with mental health disorders $(\mathbf{N}=406)$

\begin{tabular}{|c|c|c|c|c|c|c|c|c|c|}
\hline & & \multicolumn{3}{|c|}{$\begin{array}{l}\text { Bivariate analyses } \\
\text { (simple logistic } \\
\text { regression) }\end{array}$} & \multicolumn{5}{|c|}{$\begin{array}{c}\text { Multiple regression logistic (backward LR } \\
\text { elimination method) }\end{array}$} \\
\hline & & \multirow[t]{2}{*}{ Beta } & \multirow[t]{2}{*}{ Sig. } & \multirow[t]{2}{*}{ OR } & \multirow[t]{2}{*}{ Beta } & \multirow[t]{2}{*}{ Sig. } & \multirow[t]{2}{*}{ OR } & \multicolumn{2}{|c|}{$95 \%$ IC } \\
\hline & & & & & & & & Lower L. & Upper L. \\
\hline \multirow[t]{5}{*}{ Predisposing factors } & Gender (Male $=1)$ & -.576 & .004 & .562 & -.705 & .003 & .494 & .308 & .792 \\
\hline & Age & .018 & .017 & 1.019 & .019 & .039 & 1.019 & 1.001 & 1.038 \\
\hline & General satisfaction with life (= Very satisfied) & -.272 & .006 & .762 & & & & & \\
\hline & Self-perception of his physical health (= Excellent) & -.208 & .028 & .812 & & & & & \\
\hline & Self-perception of mental health (= Excellent) & -.446 & .000 & 640 & -.303 & .016 & .739 & .577 & .946 \\
\hline \multirow[t]{4}{*}{ Enabling factors } & Quality of life score & -.010 & .086 & .990 & & & & & \\
\hline & Proportion of active population aged 15 and up & .000 & .065 & 1.000 & & & & & \\
\hline & Proportion of rental accommodations & -.008 & .026 & .992 & -.010 & .013 & .990 & .982 & .998 \\
\hline & Proportion of recent immigrants (1 year) & -.094 & .094 & .910 & & & & & \\
\hline \multirow[t]{4}{*}{ Needs } & Lifetime victim of violence & 1.222 & .000 & 3.393 & .997 & .000 & 2.710 & 1.698 & 4.327 \\
\hline & Lifetime aggressive behaviour & .678 & .001 & 1.971 & & & & & \\
\hline & Emotional problems in the 12 months pre-interview & 1.850 & .000 & 6.358 & 1.532 & .000 & 4.629 & 2.870 & 7.465 \\
\hline & & & & & \multicolumn{5}{|c|}{$\begin{array}{l}\text { Hosmer-Lemeshow test: } \\
\text { Khi-square }=13.717 ; P=0.089 \\
\text { Nagelkerke } R^{2}: 33.6 \%\end{array}$} \\
\hline
\end{tabular}


increasing the risk of developing mental disorders $[52,87,88]$, and the subjective sense of having emotional problems [54]. Females who are victims both of physical and sexual violence are up to 14 times more likely to develop post-traumatic stress disorder, and five to eight times more likely to experience a serious depressive episode than females who have not been exposed to violence [87]. Furthermore, having a mental disorder increases the risk of exposure to violence. Victimisation is especially prevalent among individuals with serious mental disorders. Depending on the type of violent crime, the risk of the latter being a crime victim is six to twenty-three times greater than among the general population [88]. Psychiatric surveys do not usually show the percentage of individuals who are lifetime victims of violence; consequently, that variable is not analysed in studies on service use with respect to mental disorders. It wasn't possible to ascertain, however, if victims of violence were over represented in our sample.

With regards to predisposing factors, our results were consistent with previous findings that females were more likely to use health services $[2,29,36,38]$. However, women's greater propensity for using health services is not associated with a greater prevalence of mental disorder among them. In Quebec, the suicide rate among men is nearly four times greater than among women; in addition, substance-related disorders are significantly more frequent among men [20]. According to several authors, females have a greater facility for identifying and accepting mental health diagnoses, which may account for their more frequent use of mental health services $[7,38]$.

The association between age and health service utilisation has been frequently noted in the literature $[2,8,29,35,89]$. In our sample, the mean age was roundly 39 years old (SD 13.1); participants were thus predominantly middle-aged. According to studies, these individuals were more likely to use services than those under 25 and those over $65[8,34,35]$. Younger adults tend not to perceive their need for treatment, and often prefer to solve problems by themselves [35]. They are also more likely to drop out of treatment [89]. Conversely, older individuals with mental disorders usually present more stable conditions, which may explain their preference for general practitioners as the main providers of health services [29]. The fear of stigmatisation may also contribute to lower health service use among young adults, and persons aged over 65 years old as compared with individuals in between [90].

The association between poor self-perception of mental health and health service use is evident. The failure to recognise a problem is a serious obstacle to health service access [49]. Accepting the need for mental health may be a challenge for individuals who are shy or who have high self-esteem [49]. Self-perception with regard to mental health or attitudes toward health services may account for differences between males and females [80]. Males are usually more reluctant to recognise their emotional or mental problems [80] and take longer to seek help [7,37].

The only enabling variable associated with health service use within a neighbourhood was the ratio of renters to homeowners. Neighbourhoods with more rental housing may be characterised by weaker residential stability. Conversely, homeowners may feel a greater sense of belonging to their neighbourhood. As they are less likely to move than renters, homeowners probably possess a better understanding of health services in their neighbourhood and may even have used them regularly for a long period. Moreover, residential stability fosters the development of stronger ties with neighbours that can help individuals to identify their problems and determine what to do to resolve them $[49,52]$. Perhaps, neighbourhoods with a larger proportion of homeowners also enjoy higher percapita income. Individuals with higher socio-economic status have access to a greater range of resources [2], such as private psychologists whose services are not covered by the public healthcare insurance system in Quebec.

\section{Limitations}

This study has some limitations. First, it did not include the full spectrum of psychiatric disorders, for example, schizophrenia and other serious mental disorders, organic mental disorders, sexual disorders, eating disorders, personality disorders or intellectual deficiencies. Individuals with severe mental disorders have been heavy service users [91-93]. Second, we did not take into account the severity of mental disorder. Previous studies have reported that severe cases were associated with more intensive service use than mildly severe or moderate cases $[11,12]$. Third, we didn't have information about the duration of, or access to health service use. According to Leaf and colleagues, health service use is associated with having a regular source of medical care [34]. Long delays between the onset of disease and first contact with a health provider represent a significant obstacle to health service use [7]. Fourth, the observed correlations between health service use and the diverse variables didn't imply causality. Finally, the value of this study may be limited to information regarding the specific city or the specific catchment area that was investigated.

\section{Conclusion}

The present study is of interest as it analysed a comprehensive set of variables, including geospatial factors. To our knowledge, no previous study has focused on such numerous variables using the Andersen behavioural model. This catchment area study also made an original contribution by targeting individuals diagnosed with mental disorders exclusively as against much of the literature which focuses on the general population. 
As reported in previous studies, an unusually high proportion of individuals with mental disorders did not use health services. If decision-makers and practitioners are to improve the efficacy of the mental health system, they must gain a better understanding of factors that drive the utilisation or non-utilisation of services. This study broke new ground by uncovering the importance of two novels variables (longstanding violence victimisation, and the proportion of homeownership), associated with health service use among individuals with mental disorders. Stress and pain caused by needs-related factor or health belief variable (longstanding violence victimisation, emotional problems, self-perceived mental health) may lead individuals to seek health services for mental health reasons. In addition, targeting neighbourhoods with high proportion of rental accommodations could be a public health priority to improve service utilization and mental health. Finally, as reported in previous research, age and gender were associated with health service use. Males and youths used significantly fewer mental health services than females and middle-aged individuals. Accordingly, strategies aimed at changing attitudes among males and youths should be promoted. Globally, this study encourages the reinforcement of public education, and services designed especially to target populations (youths and males, rental housing neighbourhoods), in view of helping individuals with mental disorders or reducing their reluctance to seek health services.

\section{Acknowledgements}

The study was funded by the Canadian Institute of Health Research (CIHR). We would like to thank this grant agency, and all the individuals who participated in the research.

\section{Author details \\ 'Department of Psychiatry, McGill University, Douglas Hospital Research Centre, 6875 LaSalle Blvd., Montreal, Quebec H4H 1R3, Canada. ${ }^{2}$ Douglas Hospital Research Centre, 6875 LaSalle Blvd., Montreal, Quebec H4H 1R3, Canada. ${ }^{3}$ Department of Social and Preventive Medicine, University of Montreal, 3850, St-Urbain Street, Montreal, Quebec H2W 1T7, Canada.}

\section{Authors' contributions}

MJF, GG and MP designed the study. JMB carried out the statistical analyses with assistance from JC directing the full catchment area study. MJF and GG wrote the article. YK built the geospatial data-bank used in the study, and helped to write the methodological section. All authors have read and approved the final manuscript.

\section{Competing interests}

The authors declare that they have no competing interests.

Received: 9 November 2011 Accepted: 2 April 2012

Published: 2 April 2012

\section{References}

1. Dewa CS, Lesage A, Goering P, Craven M: Nature and prevalence of mental illness in the workplace. Healthc Pap 2004, 5(2):12-25.

2. Vasiliadis HM, Lesage A, Adair C, Wang PS, Kessler RC: Do Canada and the United States differ in prevalence of depression and utilization of services. Psychiatr Serv 2007, 58(1):63-71.
3. Wang PS, Beck AL, Berglund P, McKenas DK, Pronk NP, Simon GE, Kessler RC: Effects of major depression on moment-in-time work performance. Am J Psychiatry 2004, 161(10):1885-1891.

4. Kessler RC, Berglund P, Demler O, Jin R, Koretz D, Merikangas KR, Rush AJ, Walters EE, Wang P: Replication NCS. The epidemiology of major depressive disorder. Results from the National Comorbidity Survey Replication (NCS-R). JAMA 2003, 289(23):3095-3105.

5. Mojtabai R, Olfson M, Mechanic D: Perceived need and help-seeking in adults with mood, anxiety, or substance use disorders. Arch Gen Psychiatry 2002, 59(1):77-84.

6. Kessler RC, Zhao S, Katz SJ, Kouzis AC, Frank RG, Edlund M, Leaf P: Past-year use of outpatient services for psychiatric problems in the National Comorbidity Survey. Am J Psychiatry 1999, 156(1):115-123.

7. Wang PS, Berglund P, Olfson M, Pincus HA, Wells KB, Kessler RC: Failure and delay in initial treatment contact after first onset of mental disorders in the National Comorbidity Survey Replication. Arch Gen Psychiatry 2005, 62(6):603-613.

8. Wang PS, Lane M, Olfson M, Pincus HA, Wells KB, Kessler RC: Twelve-month use of mental health services in the United States. Arch Gen Psychiatry 2005, 62(6):629-640.

9. Vasiliadis H-M, Lesage A, Adair C, Boyer R: Service use for mental health raisons: cross-provincial difference in rates, determinants, and equity of access. Can J Psychiatry 2005, 50(10):614-619.

10. Wittchen $\mathrm{H}-\mathrm{U}$, Jacobi F: Size and burden of mental disorders in Europe a critical review and appraisal of 27 studies. Eur Neuropsychopharmacol 2005, 15(4):357-376.

11. Tempier R, Meadows GN, Vasiliadis HM, Mosier KE, Lesage A, Stiller A, Graham A, Lepnurm M: Mental disorders and mental health care in Canada and Australia: comparative epidemiological findings. Soc Psychiatry Psychiatr Epidemiol 2009, 44(1):63-72.

12. Wang PS, Aguilar-Gaxiola S, Alonso J, Angermeyer MC, Borges G, Bromet EJ, Bruffaerts R, de Girolama G, de Graff R, Gureje O, et al: Use of mental health services for anxiety, mood, and substance disorders in 17 countries in the WHO world mental health surveys. Lancet 2007, 370(9590):841-850

13. Lesage A, Vasiliadis H-M, Gagné M-A, Dudgeon S, Kasman N, Hay C: Prevalence of mental illness and related service utilization in Canada: an analysis of the Canadian Community Health Survey. Mississauga, Ontario: Canadian Collaborative Mental Health Initiative; 2006.

14. Andersen RM: Revisiting the behavioral model and access to medical care: does it matter? J Health Soc Behav 1995, 36(1):1-10.

15. Tsao JC, Dobalian A, Myers CD, Zeltzer LK: Pain and use of complementary and alternative medicine in a national sample of persons living with HIV. J Pain Symptom Manage 2005, 30(5):418-432.

16. Digiusto $E$, Treloar C: Equity of access to treatment, and barriers to treatment for illicit drug use in Australia. Addiction 2007, 102(6):958-969.

17. Vingilis E, Wade T, Seeley J: Predictors of adolescent health care utilization. J Adolesc 2007, 30(5):773-800.

18. Chou YC, Lee YC, Lin LC, Chang AN, Huang WY: Social services utilization by adults with intellectual disabilities and their families. Soc Sci Med 2008, 66(12):2474-2485.

19. Lin E, Goering PN, Lesage A, Streiner DL: Epidemiologic assessment of overmet need in mental health care. Soc Psychiatry Psychiatr Epidemiol 1997, 32(6):355-362.

20. Lefebvre J, Lesage A, Cyr M, Toupin J, Fournier L: Factors related to utilization of services for mental health reasons in Montreal, Canada. Soc Psychiatry Psychiatr Epidemiol 1998, 33(6):291-298.

21. Bijl RV, Ravelli A: Psychiatric morbidity, service use, and need for care in the general population: results of the netherlands mental health survey and incidence study. Am J Public Health 2000, 90(4):602-607.

22. Goodwin R, Andersen RM: Use of the behavioral model of health care use to identify correlates of use of treatment for panic attacks in the community. Soc Psychiatry Psychiatr Epidemiol 2002, 37(5):212-219.

23. Elhai JD, Grubaugh AL, Richardson JD, Egede LE, Creamer M: Outpatient medical and mental healthcare utilization models among military veterans: Results from the 2001 National Surveys of Veterans. J Psychiatr Research 2008, 42(10):858-867.

24. Thorpe JM, Van Houtven CJ, Sleath BL, Thorpe CT: Rural-urban differences in preventable hospitalizations among community-dwelling veterans with dementia. J Rural Health 2010, 26(2):146-155. 
25. Choi S, Rozario P, Morrow-Howell N, Proctor E: Elders with first psychiatric hospitalization for depression. Int J Geriatr Psychiatry 2009, 24(1):33-40.

26. Kamble P, Chen H, Sherer J, Aparasu RR: Antipsychotic drug use among elderly nursing home residents with dementia in the United States. Am J Geriatr Pharmacother 2009, 6(4):187-197.

27. Fleury M-J, Grenier G, Bamvita J-M, Caron J: Professional service utilisation among patients with severe mental disorders. BMC health services research 2010, 10:141.

28. Fleury M-J, Grenier G, Bamvita J-M, Caron J: Mental health service utilization among patients with severe mental disorders. Community Ment Health J 2010, 47(4):365-377.

29. Carr VJ, Johnston PJ, Lewin TJ, Rajkumar S, Carter GL, Issakidis C: Patterns of service use among persons with schizophrenia and other psychotic disorders. Psychiatr Serv 2003, 54(2):226-235

30. Hatzenbuehler ML, Keyes KM, Narrow WE, Grant BF, Hasin DS: Racial/ethnic disparities in service utilization for individuals with co-occurring mental health and substance use disorders in the general population. $J$ Clin Psychiatry 2008, 69(7):1112-1121.

31. Lemming MR, Calsyn RJ: Utility of the behavioral model in predicting service utilization by individuals suffering from severe mental illness and homelessness. Community Ment Health J 2004, 40(4):347-364.

32. Lipsky S, Caetano R, Roy-Byrne P: Triple jeopardy; impact of partner violence perpetration, mental health and substance abuse on perceived unmet for mental health care among men. Soc Psychiatry Psychiatr Epidemiol 2010, 46(9):843-852

33. Keyes KM, Hatzenbuehler ML, Alberti P, Narrow WE, Grant BF, Hasin DS: Service utilization differences for Axis I psychiatric and substance use disorders between white and black adults. Psychiatr Serv 2008, 59(8):893-901.

34. Leaf PJ, Livingston MM, Tischler GL, Weissman MM, Holzer CE, Myers JK: Contact with health professionals for the treatment of psychiatric and emotional problems. Med Care 1985, 23(12):1322-1337.

35. Kessler RC, Berglund PA, Bruce ML, Koch JR, Laska EM, Leaf PJ, Mandercheid RW, Rosenheck RA, Walters EE, Wang PS: The prevalence and correlates of untreated serious mental illness. Health Serv Res 2001, 36(6):987-1007.

36. Narrow WE, Regier DA, Norquist G, Rae DS, Kennedy C, Arons B: Mental health service use by Americans with severe mental illness. Soc Psychiatry Psychiatr Epidemiol 2000, 35(4):147-155.

37. Putkonen $\mathrm{H}$, Weizman-Henelius $\mathrm{G}$, Lindberg N, Romano T, HäkkänenNyholm H: Gender differences in homicide offenders' criminal career, substance abuse and mental health care. A nationwide register-based study of Finnish homicide offender 1995-2004. Crim Behav Ment Health 2011, 21(1):51-62.

38. Uebelacker LA, Wang PS, Berglund P, Kessler RC: Clinical differences among patients treated for mental health problems in general medical and specialty mental health settings in the National Comoribidity Survey Replication (NCS-R). Gen Hosp Psychiatry 2006, 28(5):387-395.

39. Wells KB, Manning WG, Duan N, Newhouse JP, Ware JE Jr: Sociodemographic factors and the use of outpatient mental health services. Med care 1986, 24(1):75-85.

40. Bebbington $P$, Meltzer $H$, Brugha TS, Farrell $M$, Jenkins $R$, Ceresa $C$, Lewis G: Unequal access and unmet need: neurotic disorders and the use of primary care services. Psychol Med 2000, 30(6):1359-1367.

41. Parslow RA, Jorm AF: Who uses mental health services in Australia? An analysis of data from the National Survey of Mental Health and Wellbeing. Aust N Z J Psychiatry 2000, 34(6):997-1008.

42. Olfson M, Marcus SC, Druss B, Pincus HA: National trends in the use of outpatient psychotherapy. Am J Psychiatry 2002, 159(11):1914-1920.

43. Young AS, Klap R, Sherbourne CD, Wells KB: The quality of care for depressive and anxiety disorders in the United States. Arch Gen Psychiatry 2001, 58(1):55-61.

44. Wang PS, Berglund P, Kessler RC: Recent care of common mental disorders in the United States: prevalence and conformance with evidence-based recommendations. J Gen Intern Med 2000, 15(5):284-292

45. Hendryx MS, Ahern MM: Acess to mental health services and health sector social capital. Adm Policy Ment Health 2001, 28(3):205-217.

46. Alegria M, Bijl RV, Lin E, Walters EE, Kessler RC: Income differences in persons seeking outpatient treatment for mental disorders. Arch Gen Psychiatry 2000, 57(4):383-391.
47. Pescosolido BA, Gardner CB, Lubell KM: How people get into mental health services: stories of choice, coercion and "muddling through" from "first-timers". Soc Sci Med 1998, 46(2):275-286.

48. Albert M, Becker T, McCrone P, Thornicroft G: Social networks and mental health service utilisation. A literature review. Int J Soc Psychiatry 1998, 44(4):248-266

49. Howard KI, Cornille TA, Lyons JS, Vessey JT, Lueger RJ, Saunders SM: Patterns of mental health service utilization. Arch Gen Psychiatry 1996, 53(8):696-703.

50. Bonin J-P, Fournier $L$, Blais R: Predictors of mental health service utilization by people using resources for homeless people in Canada. Psychiatr Serv 2007, 58(7):936-941.

51. Galea S, Ahern J, Rudenstine S, Wallace Z, Vlahow D: Urban built environment and depression: a multilevel analysis. J Epidemio/ Comnmunity Health 2005, 59(10):822-827.

52. Stockdale SE, Wells KB, Tang $L$, Belin TR, Zhang $L$, Sherbroune CD: The importance of social context; neighborhood stressors, stress-buffering mechanisms, and alcohol drug, and mental health disorders. Soc Sci Med 2007, 65(9):1867-1881.

53. Amstadter A, Zinzow HM, McCauley JL, Strachan M, Ruggerio KJ, Resnick HS, Kilpatrick DG: Prevalence and correlates of service utilization and help seeking in a national college sample of female rape victims. Anxiety Disord 2010, 24(8):900-902.

54. Brand B: Trauma and women. Psychiatr Clin North Am 2003, 26(3):759-579.

55. Caron J, Tousignant $M$, Pedersen D, Fleury M-J, Cargo M, Daniel M, Kestin $Y$, Crocker A, Perreault M, Brunet A, et al: La création d'une nouvelle génération d'études épidémiologiques en santé mentale. Sante Ment Que 2007, 32(2):225-238.

56. Singer E: Nonresponse bias in household surveys. Public Opin Q 2006, 70(5):637-645

57. Morton LM, Cahill J, Hartge P: Reporting participation in epidemiologic studies: a survey of practice. Am J Epdemiol 2006, 163(3):197-203.

58. NPHS: National Public health Survey (NPHS) Ottawa: Statistics Canada:2003-2005

59. Baker F, Intagliata J: Quality of life in the evaluation of community support systems. Eval Program Plann 1982, 5(1):69-79.

60. Driessen G, Gunther N, Van Os J: Shared social environment and psychiatric disorder: a multilevel analysis of individual and ecological effects. Soc Psychiatry Psychiatr Epidemiol 1998, 33(12):606-612.

61. Perkins DD, Long DA: Neighborhoud sense of community and social capital: A multi-level analysis. In Psychological sense of community: Research, applications and implications. Edited by: Fisher AT, Sonn CC, Bishop BJ. New York: Plenum; 2002:291-318.

62. Saegert S, Winke G: Crime, social capital, and community participation. Am J Community Psychol 2004, 34(3-4):219-233.

63. Nario-Redmond MR, Coulton CJ, Milligan SE: Measuring resident perceptions of neighborhood conditions: Survey methodology. Cleveland, Ohio: Case Western Reserve University, Mandel School of Applied Social Sciences, Center on Urban Poverty and Social Change; 2000.

64. Sampson RJ, Morenoff JD, Gannon-Rowley T: Assessing neighborhood effects: social processes and new directions in research. Annu Rev Soc 2002, 28:443-478.

65. Coulton CJ, Korbin JE, Su M: Measuring neighborhood context for young children in an urban area. Am J Community Psychol 1996, 24(1):5-32

66. Cutrona CE: Behavioral manifestation of social support: a microanalytic investigation. J Pers Soc Psychol 1986, 51(1):201-208.

67. Tohen M, Bromet E, Murphy JM, Tsuang MT: Psychiatric epidemiology. Harv Rev Psychiatry 2000, 8(3):111-125.

68. Andrade L, Caraveo-Anduaga JJ, Berglund P, Bijl RV, Kessler RC, Demler O, Walters EE, Kylyc C, Offord D, Üstün TB, et al: Cross-national comparisons of the prevalences and correlates of mental disorders. Bulletin World Health Organization 2000, 78(4):421-426

69. Skinner HA: The Drug Abuse Screening Test. Addictive Behaviors 1982 , 7(4):363-371

70. Bohn MJ, Babor TF, Kranzler HR: The Alcohol Use Disorders Identification Test (AUDIT): validation of a screening instrument for use in medial settings. J Stud Alcohol 1995, 56(4):423-432.

71. Kay SR, Woldkenfied F, Murrill LM: Profiles of aggression among psychiatrist patients. J Nerv Ment Dis 1988, 176(9):539-546.

72. Kessler RC, Barker PR, Colpe LJ, Epstein JF, Gfroerer JC, Hiripi E, Howes MJ, Normand S-L, Mandercheid RW, Walters EE, et al: Screening for serious 
mental illness in the general population. Arch Gen Psychiatry 2003, 60(2):184-189.

73. Barratt ES: Impulsiveness subtraits: Arousal and information processing. In Motivation, emotion and personality. Edited by: Spence JT, Izards CE. North Holland: Elsevier Science Publishers; 1985:137-146.

74. Kessler RC, Andrews G, Mroczek D, Ustun B, Wittchen HU: The World Health Organization Composite International Diagnostic Interview Short From (CIDI-SF). Int J Methods Psychiatr Res 1998, 7(4):171-185.

75. Wittchen HU: Reliability and validity studies of the WHO-Composite International Diagnostic Interview (CIDI): a critical review. J Psychiatr Res 1994, 28(1):57-84.

76. Oliver LN, Schuurman N, Hall AW: Comparing circular and network buffers to examine the influence of land use on walking for leisure and errands. Int J Health Geographics 2007, 6:41.

77. Field A: Discovering statistics using SPSS. 2 edition. London: Sage; 2005.

78. Kessler RC, Demler O, Frank RG, Olfson M, Pincus HA, Walters EE, Wang PS, Wells KB, Zaslavsky AM: Prevalence and treatment of mental disorders, 1990 to 2003. N Engl J Med 2005, 352(24):2515-2523.

79. Andrews G, Henderson S, Hall W: Prevalence, comorbidity, disability and service. Br J Psychiatry 2001, 178:145-153.

80. Andrews G, Issakidis C, Carter G: Shortfall in mental health service utilisation. British Journal of Psychiatry 2001, 179:417-425.

81. Najim H, McCrone P: The Camberwell Assessment of Need: comparison of assessments by staff and patients in an inner-city and a semi-rural community area. Psychiatr Bull 2005, 29(1):13-17.

82. McCrone P, Leese M, Thornicroft G, Griffith G, Padfield S, Schene AH, Knudsen HC, Vazquez-Barquero JL, Lasalvia A, White IR: Reliability of the Camberwell Assessment of Need- European Version. EPSILON Study 6. European Psychiatric Services: Inputs inked to outcome domains and needs. Br J Psychiatry Suppl 2000, 39:s34-s40

83. Whisman MA, Uebelacker LA: Impairment and distress associated with relationship discord in a national sample of married or cohabiting adults. J Fam Psychol 2006, 20(3):369-377.

84. Caron J, Latimer E, Tousignant M: Predictors of psychological Distress in Low-income populations of Montreal. Can J Public Health 2007, 98(1): s35-s44.

85. Schonbrun YC, Whismam MA: Marital distress and mental health care service utilization. J Consult Clin Psychol 2010, 78(5):732-736.

86. Prigerson HG, Maciejewski PK, Rosenheck RA: The effects of marital dissolution and marital quality on health and health service use among women. Med Care 1999, 37(9):858-873.

87. Hedtke KA, Ruggiero KJ, Fitzerald MM, Zinzow HM, Saunders BE, Resnick HS, Kilpatrick DG: A longitudinal investigation of interpersonal violence in relation to mental health and substance use. J Consult Clin Psychol 2008, 76(4):633-647.

88. Teplin LA, McClelland GM, Abram KM, Weiner DA: Crime victimization in adults with severe mental illness: comparison with the National Crime Victimization Survey. Arch Gen Psychiatry 2005, 62(8):911-921.

89. Edlund MJ, Wang PS, Berglund PA, Katz SJ, Lin E, Kessler RC: Dropping out of mental health treatment: patterns and predictors among epidemiological survey respondents in the United States and Ontario. Am J Psychiatry 2002, 159(5):845-851.

90. Kessler RC, Chiu WT, Demler O, Walters EE: Prevalence, severity, and comorbidity of 12-month DSM-IV disorders in the National Comorbidity Survey Replication. Arch Gen Psychiatry 2005, 62(6):617-627.

91. Kent $S$, Fogarty $M$, Yellowlees P: A review of studies of heavy users of psychiatric services. Psychiatr Serv 1995, 46(12):1247-1253.

92. Kent $S$, Yellowlees $P$ : The relationship between social factors and frequent use of psychiatric services. Aust N Z Psychiatry 1995, 29(3):403-408.

93. Chaput YJ, Lebel M-J: Demographic and clinical profiles of patients who make multiple visits to psychiatric emergency services. Psychiatr Serv 2007, 58(3):335-341.

doi:10.1186/1475-9276-11-20

Cite this article as: Fleury et al:: Comprehensive determinants of health service utilisation for mental health reasons in a canadian catchment area. International Journal for Equity in Health 2012 11:20.

\section{Submit your next manuscript to BioMed Central and take full advantage of:}

- Convenient online submission

- Thorough peer review

- No space constraints or color figure charges

- Immediate publication on acceptance

- Inclusion in PubMed, CAS, Scopus and Google Scholar

- Research which is freely available for redistribution

Submit your manuscript at www.biomedcentral.com/submit
C Biomed Central 